\title{
"Ajudar os Outros me Deixa Feliz": Voluntariado e Felicidade no Projeto Acesso Cidadão
}

\author{
Aline Fabia Guerra de Moraes \\ Universidade Federal de Minas Gerais - Brasil \\ lineguerra@hotmail.com \\ Alice Gerlane Cardoso da Silva \\ Universidade Federal de Minas Gerais - Brasil \\ alicegerlane@hotmail.com \\ Carlos Eduardo Cavalcante \\ Universidade Federal da Paraíba - Brasil \\ cavalcanteeduardo@gmail.com \\ Amanda Florense Alves Amorim \\ Universidade Federal da Paraíba - Brasil \\ amanda_ipnv@hotmail.com
}

\section{Resumo}

O presente estudo objetivou identificar relações entre motivação e felicidade no trabalho dos voluntários do Projeto Acesso Cidadão. Para abordar a felicidade foi utilizado instrumento composto por fatores como afetos positivos, afetos negativos e realização no trabalho. Para mensurar os aspectos motivacionais do trabalhador voluntário foi utilizado instrumento que identifica uma hierarquia de ações, proposta em cinco níveis: altruísta, afetivo, amigável, ajustado e ajuizado. As análises demonstraram que os elementos relacionados ao bem-estar impactam positivamente na motivação dos voluntários. Conclui-se que o nível altruísta aparece em maior proporção como motivador e, que os fatores egoístas não demonstraram resultados representativos.

Palavras-chave: felicidade, trabalho voluntário, motivação de voluntários, terceiro setor 


\title{
"I Feel Happy Helping Others": Volunteering and Happiness at Acesso Cidadão Project
}

\author{
Aline Fabia Guerra de Moraes \\ Universidade Federal de Minas Gerais - Brasil \\ lineguerra@hotmail.com \\ Alice Gerlane Cardoso da Silva \\ Universidade Federal de Minas Gerais - Brasil \\ alicegerlane@hotmail.com \\ Carlos Eduardo Cavalcante \\ Universidade Federal da Paraíba - Brasil \\ cavalcanteeduardo@gmail.com \\ Amanda Florense Alves Amorim \\ Universidade Federal da Paraíba - Brasil \\ amanda_ipnv@hotmail.com
}

\begin{abstract}
This study aimed to identify the relationship between motivation and happiness in the work of the Citizen Access Project volunteers. To address the happiness was used instrument composed of factors such as positive affect, negative affect and fulfillment at work. To approach the motivational aspects of voluntary work was used instrument that identifies a hierarchy of actions proposed in five levels: selfless, affectionate, friendly, adjusted and filed. Analysis showed that the elements related to the welfare positively impact the motivation of volunteers. It is concluded that altruistic level appears in greater proportion as a motivator and that selfish factors did not show representative results.
\end{abstract}

Keywords: happiness, volunteering, volunteer motivations, non-profit sector 
Ao longo dos anos o trabalho tem contribuído para a sobrevivência e adaptação dos indivíduos no mundo, tornando-se extremamente relevante na vida das pessoas. Por isso, a importância do trabalho tem sido plausivelmente discutida na literatura científica. Considerando que é no ambiente de trabalho que os indivíduos dedicam boa parte de seu tempo, torna-se essencial a discussão e investigação de temas relacionados à felicidade no trabalho, uma vez que, essa é uma área que ainda não possui concepções claras (Siqueira \& Padovam, 2008). Alguns estudos objetivam discutir a respeito da felicidade e do bem-estar no trabalho, reconhecendo a importância destas variáveis, tendo em vista que uma vez bem compreendidas, podem proporcionar aos indivíduos melhores condições de trabalho e, inclusive, de vida (Ryan \& Deci, 2001; Silva \& Tolfo, 2012; Rocha \& Porto, 2012; Gomide, Silvestrin \& Oliveira, 2015).

Nesta perspectiva, existem estudos que buscam a compreensão da felicidade a partir das experiências de prazer versus desprazer, enquanto outros afirmam que os pesquisadores procuram entender o tema a partir da identificação de o quanto às pessoas se consideram felizes. (Ryan \& Deci, 2001; Siqueira \& Padovam, 2008). Nesse contexto, pesquisas sobre felicidade têm crescido nos últimos anos, tendendo a aliar a ideia de bem-estar ao estudo científico da felicidade (Albuquerque \& Tróccoli, 2004; Paschoal, Torres \& Porto, 2010). Entretanto, embora os estudiosos sejam cientes da relevância do estudo da felicidade no trabalho, existem poucos modelos teóricos e empíricos sobre o bem-estar laboral e sobre as causas que o determinam (Paschoal, 2008).

O bem-estar (aqui tratado na perspectiva do trabalho) advém de trocas estabelecidas entre os trabalhadores e as organizações, podendo ser afetadas por diversos elementos, a exemplo do monetário, como o salário (Paz \& Tamayo, 2004). Contudo, um contexto específico de trabalho não tem como motivador o elemento financeiro e pode ter como consequências ligadas ao bem-estar e à felicidade: o trabalho voluntário. Estudos demonstram que o voluntariado, sendo um campo de atuação no qual não se tem como fim o lucro, tem-se apresentado como um propiciador de recompensas subjetivas para aqueles que desenvolvem trabalho voluntário, tais como benefícios ligados a saúde física e mental (Lum \& Lightfoot, 2005; Tang, Morrow-Howell \& Hong 2009; Souza, Lautert \& Hilleshein, 2010; Parizotto \& Freitas, 2015).

Os benefícios individuais associados com voluntários têm sido bem documentados na literatura, em especial, benefícios relacionados com a saúde de voluntários adultos mais velhos, pois os mesmos, em comparação com os não voluntários, apresentam-se mais 
propensos a experimentar níveis superiores de satisfação com a vida, maior bem-estar, diminuição da dependência física, e menores taxas de mortalidade (Tang et al., 2009). Muitas iniciativas públicas e privadas têm buscado encorajar as pessoas idosas a permanecerem envolvidos na aposentadoria, em atividades produtivas, tais como o voluntariado, uma vez que há alegações frequentes de que o voluntariado formal não só fornece um valioso serviço à comunidade, mas também realmente melhora a saúde física e mental, e talvez até mesmo afeta a longevidade (Lum \& Lightfoot, 2005).

Neste sentido, uma pesquisa realizada com idosos (Souza et al., 2010) que desenvolvem trabalho voluntário, constatou a partir de um modelo de regressão linear que este tipo de atividade impacta significativamente na melhor qualidade de vida, no domínio psicológico e na avaliação global destes idosos. De modo a corroborar com esta informação, um estudo com jovens voluntários (Parizotto \& Freitas, 2015) analisou os motivos que contribuem para que as pessoas desenvolvam atividades em prol do bem-estar e da satisfação do outro. Nos seus resultados foi constatado que o serviço voluntário produz verdadeira felicidade naqueles que praticam, por estes encontrarem a capacidade de fazer algo por outra pessoa, sem buscar dinheiro em troca. No entanto, se faz necessário destacar que as motivações humanas para o desenvolvimento de qualquer atividade, até mesmo a voluntária, não são padronizadas, mas variam a depender das pessoas, das situações e do contexto. Até mesmo atitudes substantivas de ajuda ao próximo de modo voluntário podem ser impulsionadas por motivações egoístas (Cavalcante, 2012).

Diante do exposto, o presente estudo apresenta como objetivo analisar a relação existente entre diferentes motivações e felicidade no trabalho dos voluntários. Para esse fim, foi escolhido o Projeto Acesso Cidadão, realizado na praia do Cabo Branco, na cidade de João Pessoa - PB.

O Acesso Cidadão acontece semanalmente e está ativo há pouco mais de 2 anos, contudo, o mesmo existe há quase 3 anos. Os meses iniciais, segundo o coordenador do projeto, Genilson Machado, foram para resolução de burocracias. O projeto faz parte da ONG AC Social, instituição que busca promover ações de inclusão a pessoas com deficiência. Parcerias com o Governo do Estado, Prefeitura Municipal, FUNAD (Fundação de Apoio ao Deficiente) e Fundação Casa José Américo também foram realizadas a fim de garantir o bom andamento do projeto.

O Projeto tem como objetivo levar acesso à cultura, lazer e esporte as pessoas com deficiência ou dificuldades de locomoção. Atividades como banho de mar em cadeiras 
anfíbias, vôlei sentado, caiaque, entre outras são ofertadas para os beneficiados. Para isso, o projeto conta com cerca de 47 voluntários cadastrados, os quais passam por um curso de primeiros socorros, oferecidos pela Corpo de Bombeiros Militar da Paraíba. Assim, essa instituição pode ser ambiente privilegiado para o estudo da relação entre felicidade e trabalho voluntário.

Para atingir o objetivo proposto buscou-se identificar quais são os fatores motivacionais e os aspectos de felicidade presentes nesse tipo de trabalho para, então, correlacioná-los, buscando o alcance do objetivo proposto. Assim, o presente estudo está dividido em cinco seções, sendo a primeira, esta introdução. A segunda abordará um breve referencial sobre as temáticas aqui tratadas: trabalho voluntário, motivação e felicidade no trabalho. A terceira seção constará da metodologia utilizada para o desenvolvimento da pesquisa, abordando e explicando os instrumentos utilizados. A quarta seção, analisará os dados obtidos através dos questionários aplicados e, por fim, a quinta seção comentará os achados da pesquisa sobre a relação entre a motivação e felicidade.

\section{Referencial Teórico}

\section{Trabalho Voluntário: Conceitos e Motivações}

O crescimento das organizações solidárias, situadas dentro do chamado Terceiro Setor, pode ser visto como reflexo da crise do Estado e das estreitas relações entre mercados. Alguns autores discordam dessa ideia ao afirmarem que o surgimento deste setor é anterior a tais crises, sendo caracterizado pelo período em que os Estados Unidos buscaram liberdade ao domínio inglês, fazendo surgir associações voluntárias. No Brasil, a natureza dessas instituições estaria, por sua vez, voltada a religião (Cavalcante, 2012). No entanto, o que interessa a este trabalho é o entendimento de que essas organizações, diante de um contexto de injustiças, precarização do trabalho, entre outros males do sistema vigente, buscam reduzir os mesmos e, de certa forma, acabam contrapondo-se a dinâmica social guiada por uma lógica capitalista (Cavalcante, 2012; Cavalcante, Souza, Cunha, Nascimento \& Fernandes, 2012; Cavalcante, Souza, Cunha \& Nascimento, 2010; Teodósio, 2002).

Nessa perspectiva, o Terceiro Setor pode ser considerado o responsável por construir uma nova lógica profissional, pois, através do mesmo, novas habilidades podem ser desenvolvidas pelos trabalhadores. Atividades como capacidade de trabalhar em grupo, 
aprender a lidar com o diverso ou a trabalhar com uma quantidade menor de recursos, seriam, pois, relevantes para os trabalhadores do Terceiro Setor, impulsionando assim o voluntariado (Teodósio, 2002). Mas afinal, como se caracteriza o trabalho voluntário?

O trabalho voluntário é uma realidade que tem crescido nos últimos anos, sendo este fenômeno foco de estudos a níveis mundiais, nos quais demonstram as relevantes contribuições econômicas e sociais desta atividade. (Lum \& Lightfoot, 2005; Tang et al., 2009; Cravens, 2014). No entanto, estas mesmas pesquisas também nos apontam as inúmeras limitações nos estudos do voluntariado, a começar pelas definições de nomenclaturas que se diferenciam entre os demais lugares, não se chegando a um consenso do que, de fato, é considerado por trabalho voluntário.

Deste modo, é diante de um cenário heterogêneo quanto aos conceitos, atividades e perfis de voluntários predominantes, no qual se faz necessário assumir que neste estudo se tem por trabalho voluntário a ideia de atividades exercidas por indivíduos mediante decisão pessoal, cujo fim não está na remuneração financeira, ainda que esta seja possível se limitadas ao custo de execução, mas centra-se na busca pelo interesse, bem-estar e desenvolvimento do próximo (ONU, 2001; Musick \& Wilson, 2008, Cnaan, Handy, \& Wadsworth, 1996; Penner, 2002; Cavalcante et al. 2010; Cavalcante et al., 2012).

No Brasil, o voluntariado foi regulado através da Lei 9.608 de 18/12/1998, e, embora já se tenha descrito as principais características deste tipo de trabalho, ainda se faz relevante destacar a diferença entre o voluntariado formal e o informal. O voluntário considerado formal necessariamente deve estar associado a alguma instituição sem fins lucrativos, enquanto que o voluntário informal pode ser caracterizado como o comportamento de ajudar a um vizinho, por exemplo (Ferreira, Proença \& Proença, 2008; Cavalcante, 2012). Portanto, cabe ressaltar que este artigo considerará o voluntariado formal.

Assim, diante das definições apresentadas, nas quais demonstram o trabalho voluntário como algo que almeja doação de si pelo bem do outro, se faz necessário refletir para o fato de que através do voluntariado também se pode adquirir outros tipos de benefícios, a exemplo de recompensas afetivas, emocionais, etc. Poderíamos ainda, afirmar que as principais características para o engajamento na atividade voluntária seriam a solidariedade e, sobretudo o altruísmo (Fischer \& Schaffer, 1993; Caissie \& Halpenny, 2003; Trogdon, 2005; Prouteau \& Wolff, 2007; Cavalcante, 2012; Ageu, 2015; Aquino, 2015; Lemos, 2016; Cavalcante, 2016). No entanto, partindo do entendimento de que os interesses que movem as ações humanas são bem mais complexas, envolvendo variados e simultâneos 
agentes motivadores, se tem cada vez mais intensificado estudos para identificar as principais motivações para o trabalho voluntário (Cavalcante, 2012; Souza \& Medeiros, 2012).

Podemos entender a motivação como um conjunto de forças que levam os indivíduos a iniciarem comportamentos em relação ao trabalho e também determinam sua forma, direção e intensidade (Ferreira et al., 2008). Essa ideia de motivação é válida para o que propomos, no entanto, temos que ter em mente que as motivações dos trabalhadores voluntários são diferentes daquelas realizadas pelos trabalhadores "comuns", que recebem remuneração (Cavalcante, 2012; Souza \& Medeiros, 2012).

Algumas teorias e modelos para o voluntariado já foram criadas (Mostyn, 1983; Clary, Snyder \& Ridge, 1992; Bussell \& Forbes, 2002; Souza, Medeiros \& Fernandes, 2006; Cavalcante, 2012) com o objetivo de mensurar motivos que levam os indivíduos a se voluntariarem, além de abarcarem também as razões para sua permanência e saída das instituições que necessitam desse tipo de trabalho. Contudo, as pesquisas desse tipo ainda necessitam de estudos, e é esta afirmação que justifica, mais uma vez, o presente trabalho (Godoi \& Picoli, 2009).

A motivação para o trabalho voluntário advém dos valores individuais, da cultura, das crenças, etc. (Cavalcante et al., 2012; Cavalcante, 2016). Ao discorrermos sobre essa hierarquia das motivações, é importante deixar claro que elas servem para caracterizar os perfis de voluntários e não para qualificar o valor deste tipo de trabalho, tendo em vista que a ação voluntária será composta por algum interesse egoísta, o qual deve ocorrer em menor escala visto a natureza desse tipo de trabalho (Cavalcante, 2012). Ou seja, esclarece-se que o trabalho voluntário não vai ser mensurado a partir das hierarquias como egoísta ou não, mas que ele, entendido como uma ação espontânea, em prol do outro, também conta com interesses pessoais, por parte de alguns indivíduos, mesmo que em menor proporção (Godoi \& Picoli, 2009; Cavalcante et al., 2012).

Esta hierarquia das motivações, além de outros estudos, serviu de base para a criação de instrumento que busca mensurar as motivações, os motivos de permanência e de saída dos voluntários de seus respectivos trabalhos, através de cinco categorias que variam de fatores altruístas à egoístas (Cavalcante, 2016). O presente trabalho fez uso desta ferramenta para medir a motivação dos voluntários pesquisados. O mesmo será explicado posteriormente, na seção referente à Metodologia. 
Buscando entender os motivos que levam os trabalhadores a voluntariar-se, e cientes do significado de voluntariado (doação, caridade, altruísmo), surge a pergunta: a felicidade obtida no trabalho voluntário não seria mais um percursor da motivação? Desta, desdobramos uma segunda: existe felicidade no trabalho voluntário? Se sim, ela serve como motivador? No próximo tópico buscamos discorrer sobre felicidade, a fim de criar uma base teórica para entender esses dois fenômenos no contexto do trabalho voluntário do nosso corpus, o Acesso Cidadão.

\section{Felicidade no Trabalho Voluntário}

Buscando vencer os desafios da vida moderna, as pessoas são diariamente estimuladas a simplesmente planejar o seu dia-a-dia, esquecendo-se de avaliar seus momentos de felicidade ou de completa realização pessoal (Siqueira \& Padovam, 2008). A felicidade está totalmente vinculada às diversas esferas da vida e às diferentes atividades desenvolvidas pelo homem, sendo reconhecida como o principal elemento integrante de uma vida saudável (Diener, Scollon \& Lucas, 2003; Ryan \& Deci, 2001; Silva \& Tolfo, 2012). Esse fenômeno tem despertado atenção na academia, contudo, evita-se usar a palavra felicidade, substituindo-a por termos menos populares e mais acadêmicos (Paschoal et al., 2010). Assim, neste estudo se parte do pressuposto de que felicidade e bem-estar são sinônimos (Albuquerque \& Tróccoli, 2004; Paz \& Tamayo, 2004; Pachoal, 2008).

Diante da premissa de que a felicidade pessoal pode ser alcançada por meio do trabalho, pesquisadores do comportamento organizacional têm sido incitados a identificarem estratégias eficazes na promoção do bem-estar no ambiente laboral (Ryan \& Deci; 2001; Paschoal et al., 2010; Silva \& Tolfo, 2012; Rocha \& Porto, 2012; Gomide et al., 2015). Embora existam estudiosos empenhados em descobrir o quanto as pessoas se consideram felizes ou em que medida são capazes de realizar plenamente suas potencialidades (Siqueira \& Padovam, 2008), existem poucos modelos sobre o bem-estar laboral (Paschoal, 2008).

No entanto, existem diversas pesquisas sobre qualidade de vida, estresse ocupacional e esgotamento profissional (burnout) que representam conceitos relacionados ao bem-estar. Contudo, estudos que abordam diretamente as experiências positivas do trabalhador, buscando analisar o construto específico do bem-estar no trabalho são mais raros, 
principalmente quando a literatura científica nacional é analisada (Paschoal, 2008; Paschoal \& Tamayo, 2008; Silva \& Tolfo, 2012, Rocha \& Porto, 2012; Gomide et al.; 2015).

A concepção de bem-estar pode ser definida como felicidade em termos das emoções e humores do trabalhador (Daniels, 2000). Se partirmos desta ideia, o bem-estar no trabalho é visto como uma prevalência de emoções positivas (Paschoal \& Tamayo, 2008), sendo organizado em três fatores: aspecto positivo, negativo e realização pessoal no trabalho (Paschoal, 2008). Dessa forma, o bem-estar no trabalho pode ser compreendido em torno de duas dimensões: hedônica, que inclui afetos positivos e negativos, medidos pelas emoções e humores; e eudaimônica, que abarca aspectos cognitivos, concebidos pela percepção de expressividade e realização. O bem-estar laboral pode envolver aspectos da felicidade hedônica e se caracterizar basicamente como um estado afetivo, já o bem-estar baseado na realização, abarca o desenvolvimento de potenciais e progresso nas metas estabelecidas para vida, assim como, o estado afetivo do indivíduo (Paschoal, 2008).

Diante do exposto, torna-se pertinente analisar a felicidade no contexto do voluntariado, entendendo que a natureza do trabalho voluntário diferencia-se do organizacional. Nesse sentido, o voluntariado pode ser considerado um agente de felicidade para aqueles que nele atuam, pois embora não se tenha como foco a busca por recompensas financeiras, o trabalho voluntário tem a capacidade de gerar bem-estar e benefícios ligados a saúde física e mental (Lum \& Lightfoot, 2005; Tang et al., 2009; Souza et al., 2010; Parizotto \& Freitas, 2015).

Buscando mensurar a felicidade no trabalho, temos instrumento validado (Paschoal \& Tamayo, 2008) que inclui os aspectos afetivos e cognitivos do bem-estar laboral. A Escala de Bem-Estar no Trabalho (EBET) é um instrumento composto por 30 itens e dividido em duas partes: Afetos e Realização. A primeira, por sua vez, possui dois fatores, afeto positivo, com nove itens e afeto negativo, com doze itens. A segunda, Realização, é composta por nove itens. Sendo este, o instrumento adotado no presente estudo.

Portanto, para fins desta pesquisa, pressupõe-se que o bem-estar será mais elevado quando as emoções positivas forem mais frequentes e intensas que o afeto negativo (Paschoal et al., 2010). Dessa forma, esta definição permite que esse conceito possa ser aplicado em diferentes contextos de trabalho, organizacionais ou não (Paschoal \& Tamayo, 2008). Assim, para possibilitar que os objetos de estudo sejam contemplados de uma maneira mais abrangente, os fatores afeto positivo, afeto negativo e realização pessoal no trabalho serão retomados no momento da análise dos dados. 


\section{Método}

Este estudo busca compreender as motivações dos trabalhadores voluntários do Projeto Acesso Cidadão, assim como verificar aspectos de felicidade nesse tipo de trabalho. Para isso foram aplicados questionários entre os voluntários do projeto e em seguida, realizados procedimentos estatísticos que permitiram analisar os dados recolhidos e agrupados com base na teoria estudada.

Desse modo, podemos classificar a pesquisa como quantitativa, que teve como instrumento de coleta de dados, questionários já validados. $\mathrm{O}$ universo da pesquisa é de aproximadamente 47 indivíduos que é o número de voluntários cadastrados no Acesso Cidadão. Entretanto, o número de cadastros não corresponde, segundo o Coordenador do Projeto, ao número de voluntários efetivos. Esse número é de cerca de 30 voluntários. Assim, a amostra se deu por acessibilidade, tendo esta, o número de 23 participantes.

Para a coleta dos dados fez-se contato com o projeto através da página do mesmo em uma rede social. Neste contato foi explicada a intenção do estudo e o modo como ele seria realizado. $\mathrm{O}$ projeto por sua vez, aceitou receber a pesquisa e a ida a campo teve início. Foram realizadas duas visitas ao Projeto Acesso Cidadão, ambas realizadas nos dias de sábado, mês de Janeiro de 2014. Os dias da visita deram-se em decorrência do funcionamento do projeto ser semanal. Neste primeiro contato pessoal com o projeto, realizaram-se conversas informais com o coordenador do mesmo, assim como com voluntários, beneficiados e parentes dos beneficiados. Nesta primeira visita também foi explicado e aplicado o questionário referente a motivação, o qual será explicitado mais adiante. Na segunda visita, aplicou-se o questionário referente a felicidade no trabalho.

Os dados sobre Motivação foram coletados através de questionários validados (Cavalcante, 2012). Foram cinco os níveis de trabalho identificados na Hierarquia proposta: altruísta, afetivo, amigável, ajustado e ajuizado. Neste instrumento são desenvolvidos três modelos teóricos, que buscam recolher informações sobre expectativas, permanência e saída dos voluntários, e onde se pode observar cinco fatores de motivação que variam do altruísta ao ajuizado. Nesta pesquisa foram utilizados apenas questionários que mediam as expectativas dos voluntários, pois com exceção de um, todos estavam no projeto Acesso Cidadão a menos de um ano. 
Podemos sintetizar os fatores da seguinte forma: Altruísta, onde se tem a intenção de realizar um trabalho voluntário voltado para o bem-estar, através de convicções pessoais; Afetivo, o trabalho é motivado a partir de sentimentos de responsabilidade, sensação de dever cumprido; Amigável, aqui a decisão de se voluntariar advém do fato de se encontrarem sujeitos que convivem com situações próximas, já vivenciadas ou que se está vivenciando no grupo, há também uma busca por inserção; Ajustado, onde o voluntário busca autoconhecimento, desenvolva habilidades, ganhe status; Ajuizado, nível em que há voluntariado com a intenção de obter vantagens pessoais.

O segundo instrumento utilizado, foi o questionário EBET (Escala de Bem-Estar no Trabalho). Esta escala pode ser utilizada em diversas esferas de pesquisa, pois a mesma não foi criada especificamente para o contexto organizacional (Paschoal \& Tamayo, 2008). Sendo assim, o instrumento se aplica na investigação do presente estudo. Como já comentado, esta ferramenta é composta por 30 itens, divididos em duas partes, sendo a primeira, relacionada aos afetos subdivida em duas: Afetos Positivos (9 itens) e Afetos Negativos (12 itens), os quais abrangem emoções e humores que podem estar associados ao trabalho.

A segunda parte da escala é composta por 9 questões, que buscam investigar a Realização do indivíduo no trabalho, envolvendo o desenvolvimento de seu potencial e o alcance de suas metas. Tal instrumento conta com uma escala que vai do número 1 (onde há discordância total da resposta apresentada) até o número 5 (onde se concorda totalmente com o que foi exposto), diferente do instrumento comentado anteriormente (Cavalcante, 2012), que possui uma escala de 1 a 10, seguindo o mesmo padrão: 1 como "Discordo Totalmente" e 10 como "Concordo Totalmente".

Os dados foram analisados por meio da média, desvio padrão e coeficiente de variância para cada um dos questionários recolhidos. Foram separados 5 blocos com as respostas pertencentes a cada um deles. Estes blocos dizem respeito aos níveis de motivação descritos no modelo desenvolvido no instrumento inicialmente colocado (Cavalcante, 2012). Para cada bloco também foi retirada a média, o desvio padrão e o coeficiente de variância. Ação semelhante foi feita com o questionário EBET, contudo foram apenas 3 blocos: Afetos Positivos, Afetos Negativos e Realização.

Após a análise dos constructos separadamente, foi feito a correlação entre suas variáveis. Na correlação extraída, optou-se por analisar apenas as correlações fortes, aquelas 
que apareceram com nível de significância abaixo de ,005, pois representariam as associações entre variáveis mais relevantes.

\section{Discussão de Resultados}

Como comentado anteriormente, as teorias de motivação para o trabalho voluntário se diferenciam daquelas utilizadas para se estudar o trabalho comum, remunerado. Nesse sentido, buscamos nesta seção avaliar, primeiramente, a motivação dos voluntários do Projeto Acesso Cidadão a partir dos cinco níveis hierárquicos da motivação para o trabalho voluntário (Cavalcante, 2012). Em seguida, buscaremos analisar as variáveis referentes a felicidade, visando, por fim, encontrar correlações entre os construtos pesquisados.

A princípio, se faz necessário traçar um perfil sócio demográfico dos voluntários entrevistados. A maioria deles está no projeto Acesso Cidadão há mais de 6 meses, tendo 39\% se voluntariado há mais de um ano. Em relação ao sexo, os números são bastante próximos, tendo aproximadamente $52 \%$ de mulheres, contra $48 \%$ de homens. Esse resultado mostra equilíbrio quanto ao gênero dos voluntários.

Entre eles, a média de idade prevalece em torno dos 28 anos. Contudo, é necessário apontar que alguns números fizeram tal média subir, portanto a mesma não é um bom indicativo para essa questão. Foram encontrados voluntários que vão desde os 15, até os 57 anos, prevalecendo a faixa etária que compreende dos 20 aos 25 anos. Assim, podemos classificar os voluntários como jovens. Essa classificação ganha embasamento ao analisarmos as profissões dos mesmos, pois, ao serem indagados sobre tal, obtêm-se “estudante" como resposta em cerca de $43 \%$ dos questionários. Em relação a realização de outros trabalhos voluntários, $56 \%$ dos entrevistados já havia se voluntariado anteriormente ao Acesso Cidadão e $47 \%$ deles têm pessoas na família que também participam de ações voluntárias.

Para a análise da motivação dos voluntários, como mencionado, foram analisados cinco constructos (Altruísmo, Afetivo, Amigável, Ajustado e Ajuizado), através de questionamentos sobre as expectativas em relação ao trabalho voluntário e as razões para entrada no mesmo. As medidas utilizadas para essa análise foram a média, o desvio-padrão e o coeficiente de variância de cada bloco de questões, além das mesmas medidas para cada questão individualmente. O Quadro 1 apresenta tais medidas detalhadamente. 


\begin{tabular}{|c|c|c|c|c|c|c|c|}
\hline Perfil & Questão & $\begin{array}{l}\text { Média } \\
\text { da } \\
\text { questã } \\
\text { o }\end{array}$ & $\begin{array}{c}\text { Desvio } \\
\text { padrão } \\
\text { da } \\
\text { questã } \\
\text { o }\end{array}$ & $\begin{array}{c}\text { Coeficie } \\
\text { nte de } \\
\text { variação } \\
\text { da } \\
\text { questão }\end{array}$ & $\begin{array}{c}\text { Média } \\
\text { do } \\
\text { perfil }\end{array}$ & $\begin{array}{l}\text { Desvio } \\
\text { padrão } \\
\text { do perfil }\end{array}$ & $\begin{array}{c}\text { Coeficie } \\
\text { nte de } \\
\text { variação } \\
\text { do perfil }\end{array}$ \\
\hline \multirow{5}{*}{$\begin{array}{c}\text { Altruíst } \\
\text { a }\end{array}$} & 1 & 9,57 & 1,16 & $12,14 \%$ & \multirow{5}{*}{8,96} & \multirow{5}{*}{1,86} & \multirow{5}{*}{$20,77 \%$} \\
\hline & 2 & 9,05 & 1,46 & $16,18 \%$ & & & \\
\hline & 3 & 8,74 & 2,14 & $24,45 \%$ & & & \\
\hline & 4 & 8,96 & 2,01 & $22,45 \%$ & & & \\
\hline & 5 & 8,52 & 2,27 & $26,68 \%$ & & & \\
\hline \multirow{4}{*}{ Afetivo } & 6 & 7,74 & 2,86 & $37,00 \%$ & \multirow{4}{*}{8,55} & \multirow{4}{*}{2,02} & \multirow{4}{*}{$23,66 \%$} \\
\hline & 7 & 8,35 & 1,492 & $23,02 \%$ & & & \\
\hline & 8 & 8,91 & 1,5 & $16,88 \%$ & & & \\
\hline & 9 & 9,22 & 1,2 & $13,07 \%$ & & & \\
\hline \multirow{3}{*}{$\begin{array}{c}\text { Amigáv } \\
\text { el }\end{array}$} & 10 & 6,83 & 2,64 & $38,67 \%$ & \multirow{3}{*}{6,73} & \multirow{3}{*}{3,27} & \multirow{3}{*}{$48,53 \%$} \\
\hline & 11 & 5,91 & 2,68 & $45,30 \%$ & & & \\
\hline & 12 & 7,83 & 2,57 & $32,84 \%$ & & & \\
\hline \multirow{4}{*}{$\begin{array}{c}\text { Ajustad } \\
\text { o }\end{array}$} & 13 & 6,5 & 3,29 & $50,64 \%$ & \multirow{4}{*}{7,97} & \multirow{4}{*}{2,71} & \multirow{4}{*}{$33,96 \%$} \\
\hline & 14 & 8,39 & 2,02 & $20,03 \%$ & & & \\
\hline & 15 & 8,09 & 2,73 & $33,74 \%$ & & & \\
\hline & 16 & 8,83 & 2,23 & $25,25 \%$ & & & \\
\hline \multirow{5}{*}{$\begin{array}{c}\text { Ajuizad } \\
\text { o }\end{array}$} & 17 & 4,57 & 3,87 & $84,79 \%$ & \multirow{5}{*}{5,57} & \multirow{5}{*}{3,63} & \multirow{5}{*}{$65,32 \%$} \\
\hline & 18 & 3,65 & 3,27 & $89,53 \%$ & & & \\
\hline & 19 & 9,00 & 1,88 & $20,92 \%$ & & & \\
\hline & 20 & 5,74 & 3,28 & $57,12 \%$ & & & \\
\hline & 21 & 4,87 & 3,28 & $67,35 \%$ & & & \\
\hline
\end{tabular}

Quadro 1. Fatores motivacionais do trabalho voluntário

Fonte: Dados da pesquisa (2014)

O fator Altruísta, composto por respostas a exemplo de "ajudar os outros", "permitir que as pessoas tenham oportunidade de viver”, etc., alcançou a maior média dentre os cinco perfis analisados, 8,96, contando também com o menor desvio-padrão $(1,86)$ e coeficiente de variação de 20,77\%, o que representa homogeneidade nas respostas obtidas. Estes números representam a intenção de realizar um trabalho que promova o bem-estar, onde há um "auto sacrifício" por parte dos voluntários, como o próprio título do constructo (Altruísmo) sugere, sem esperar nada em troca (Cavalcante, 2016).

A resposta referente a "ajudar os outros", foi a que obteve maior média $(9,57)$ dentre as questões relacionadas a este primeiro fator, representando bem a ideia do fator Altruísta, sugerindo que os voluntários estão inseridos no projeto para levar a inclusão, o acesso ao 
lazer, a cultura, etc., missão do Acesso Cidadão, aos portadores de deficiência e as pessoas com dificuldades de locomoção atendidas pelo projeto.

Conforme apresentado, os dados concernentes a motivação Altruísta estão em concordância com os resultados de pesquisas anteriores (Fischer \& Schaffer, 1993), nas quais evidenciam o sentimento altruísta no voluntariado, variando-se apenas na intensidade de cada indivíduo. Nesta perspectiva ainda se faz relevante destacar que estudos internacionais (Unger, 1991; Caissie \& Halpenny, 2003; Yeung, 2004; Trogdon, 2005; Prouteau \& Wolff, 2007), bem como nacionais (Figueiredo, 2005; Cavalcante, 2012; Ageu, 2015; Aquino, 2015; Lemos, 2016; Cavalcante, 2016) demonstram que características altruístas se encontram presentes nas pessoas que engajam-se em atividades voluntárias.

O segundo perfil investigado, o Afetivo, também trouxe a segunda maior média dentre os construtos analisados, sendo ela de 8,55. O desvio-padrão encontrado foi de 2,02 e o coeficiente de variação de 23,66\%. Este coeficiente apresenta uma maior dispersão nas respostas, se comparado ao do perfil Altruísta, porém, ainda assim há coesão nas respostas dos entrevistados, confirmando assim o posicionamento de autores que afirmam ser comum o desejo das pessoas em se afiliar e pertencer a um determinado grupo através da atividade voluntária (Clary et al., 1992; Hanckinson \& Rochester, 2005; Ferreira et al., 2008).

Mediante os dados expostos, podemos considerar que os voluntários se sentem socialmente responsáveis pelo tipo de atividade realizada no Acesso Cidadão, tendo a resposta "Colaborar com a melhoria social”, a maior média $(9,22)$ dentre os indicadores do fator Afetivo. Em contrapartida, a resposta referente ao cumprimento das obrigações de cidadão foi a que recebeu menor média $(7,74)$ e maior coeficiente de variância $(37,00 \%)$ dentro deste fator, o que significa dizer que a maioria dos voluntários entendem que estão ali para auxiliar, para colaborar, não apenas para cumprir obrigações, fazer o dever de cidadão, mas sim, e reforçando a ideia do perfil Altruísta, por sentirem vontade de ajudar outras pessoas.

Ainda sobre o fator Afiliação, obteve-se como a segunda menor média $(8,35)$ deste perfil o quesito "reduzir as injustiças sociais", onde, em análise mais profunda, se pode sugerir que essas injustiças vão além do âmbito do projeto, o qual busca trazer elementos de igualdade, de acessibilidade, tentando oferecer oportunidades de lazer aos contemplados. A ideia de combater injustiças, no entanto, é mais complexa e necessita de maior organização, de contextos maiores. Assim, diante do exposto, tem-se como uma possível explicação o fato da maior parte da amostra ter entre 20 e 25 anos, pois, a afiliação como motivação para o 
trabalho voluntário torna-se presente entre pessoas jovens, sendo esta faixa etária uma das fases em que os indivíduos buscam afirmação nos grupos das quais fazem parte (Oliveira, 2010).

O terceiro fator, o Amigável, apresenta a segunda média mais baixa $(6,73)$, perdendo apenas para o fator Ajuizado, o qual será analisado mais adiante. O desvio-padrão e o coeficiente de variância desse fator foram de 3,27 e 48,53\%, respectivamente. Esses números demonstram que houve uma variação considerável nas respostas dos entrevistados. Através das respostas desse quesito, infere-se que a maioria dos voluntários não se motivaram a entrar no Projeto Acesso Cidadão objetivando conhecer novas pessoas, fazer amizades.

A resposta, dentro deste fator, que apresentou média mais baixa e coeficiente de variância mais alto foi a que se refere a "fazer parte de um grupo", tendo obtido 5,91 e 45,30\% respectivamente. Podemos entender que essas são consequências do trabalho voluntário, mas não o principal motivador dos indivíduos respondentes.

O fator Ajustado, por sua vez, sugere que os voluntários buscam novos conhecimentos, desenvolver habilidades, etc. Nesse sentido temos que no voluntariado uma das possíveis motivações das pessoas pode estar baseada na busca por aprendizado, oportunidade de novas experiências, bem como novos desafios e perspectivas (Clary et al., 1998).

As respostas para essa motivação apresentaram-se de forma um pouco dispersa. A média obtida foi de 7,97 com desvio-padrão de 2,71 e coeficiente de variância de 33,96\%, o que implica afirmar que mesmo não sendo respostas totalmente homogêneas, há aí uma certa integração entre tais. Esse fato é justificado ainda pelos valores das médias das respostas desse quesito serem de 8,39, 8,09, 8,83 e 6,50, com desvios de 2,02, 2,73, 2,23 e 3,29 e variâncias de 24, 33, 25 e 50\% aproximadamente, ou seja, há uma uniformidade nas respostas correspondentes às nas questões 14, 15 e 16, encontrando-se apenas na questão 13, diferenciação de respostas. Portanto, considera-se que novos aprendizados, assim como a busca por desenvolvimento de habilidades são razões que motivam os voluntários do Acesso Cidadão, alinhando-os a teoria que afirmam que no trabalho voluntário os indivíduos envolvidos se reafirmam como pessoas aprendendo a respeito de si enquanto ajudam outras pessoas (Silva, 2004).

Em contrapartida, se faz necessário destacar a questão 13, “Aprender a lidar com pessoas", uma vez que esta foi a única a apresentar divergências nas respostas, com uma média de 6,50. Este dado evidenciado não representa com contundência as reais motivações, 
indicando que o envolvimento com outros indivíduos, não necessariamente os motivam, e por isso, este pode ser um foco de estudo futuro.

O último fator analisado, o Ajuizado, apontou as médias mais baixas e os maiores desvios e coeficientes de variância. A média deste fator foi de 5,57, com desvio padrão de 3,63 e variância no valor de 65,32\%, inferindo-se que as respostas paras as questões que compõem esse fator foram bastante discrepantes, heterogêneas. $\mathrm{O}$ fator traz, a ideia de que os voluntários são motivados a partir da obtenção de vantagens pessoais, contudo, diante das respostas encontradas, afirma-se que quesitos como "ser reconhecido", "me sentir importante”, entre outros, não são motivadores para os voluntários do projeto.

Entretanto, a resposta 19 "Sentir-me melhor como pessoa", recebeu média 9,00 com desvio-padrão de apenas 1,88 e variância de 20,92\%, o que indica que as respostas a este questionamento foram mais homogêneas. Desse modo, se infere que os voluntários não estão em busca de reconhecimento, no entanto, desejam sentir-se melhores ajudando os outros.

Diante do exposto assume-se que, apesar dos voluntários desejarem ajudar as outras pessoas, os mesmos também buscam "recompensas", ainda que intangíveis, como obter o sentimento de melhorar como pessoa. Afinal, quando as pessoas executam trabalhos voluntários, as mesmas doam de si e ao mesmo tempo são recompensados em troca (Piccoli \& Godoi, 2009). Portanto, evidencia-se que as motivações no contexto do voluntariado podem apresentar-se contraditórias, tornando-se difícil mensurá-las em uma mesma pessoa (Fischer \& Schaffer, 1993). E embora existam motivações altruístas no voluntariado, intrinsecamente também haverá sentimentos centrados no eu, e isto não influencia o mérito da atividade voluntária (Pearce, 1983; Rose-Ackerman, 1996).

Em suma, podemos considerar que o perfil Altruísta foi o que obteve a variável com maior média, menor desvio-padrão e menor coeficiente de variância, dentre as demais analisadas, sendo assim considerada como um fator homogêneo, onde as respostas foram mais próximas e apresentando a ideia de que o principal fator motivacional para os voluntários do Acesso Cidadão, é o conceito de ajudar os outros, no caso, pessoas deficientes e/ou com dificuldades de locomoção, por entender que, de acordo com a segunda maior média, menor desvio-padrão e menor coeficiente de variância é dever, obrigação social, fazêlo. Também foi possível observar, diante dos dados, que estes voluntários não buscam reconhecimentos nem recompensas pessoais, ao contrário, exercem o ideal do voluntariado, a ajuda ao próximo sem interesses ou ganhos. Por fim, é importante mencionar, que, 
possivelmente, devido ao número da amostra ser pequeno, não foram encontradas correlações significantes entre os fatores que influenciam na motivação e o perfil sócio demográfico dos participantes. Contudo, acredita-se que esse seja apenas uma das razões para tal fato.

$\mathrm{Na}$ análise do quesito felicidade, como já comentado, utilizou-se da escala EBET (Escala de Bem-Estar no Trabalho), a qual é composta por variações que vão do número "Nem um pouco" (1) ao "Extremamente" (5), para a análise dos afetos positivos e negativos. Para aspectos relacionados a realização no trabalho, por sua vez, utilizou-se uma escola de concordância também de cinco pontos, que varia do "Discordo Totalmente" (1) ao "Concordo Totalmente" (5). A escala contou com um total de 30 itens, que tiveram suas médias, desvios e variâncias analisadas, como pode ser visto no Quadro 2.

\begin{tabular}{|c|c|c|c|c|c|c|c|}
\hline $\begin{array}{c}\text { Construct } \\
\text { o }\end{array}$ & $\begin{array}{l}\text { Quest } \\
\text { ão }\end{array}$ & $\begin{array}{l}\text { Méd } \\
\text { ia }\end{array}$ & $\begin{array}{l}\text { Desvio } \\
\text { Padrão }\end{array}$ & $\begin{array}{l}\text { Coeficient } \\
\text { e de } \\
\text { Variância }\end{array}$ & $\begin{array}{l}\text { Média do } \\
\text { Construto }\end{array}$ & $\begin{array}{c}\text { Desvio } \\
\text { Padrão } \\
\text { do } \\
\text { Construt } \\
\text { o }\end{array}$ & $\begin{array}{l}\text { Coeficient } \\
\text { e de } \\
\text { Variância } \\
\text { do } \\
\text { Construto }\end{array}$ \\
\hline \multirow{9}{*}{$\begin{array}{c}\text { Afetos } \\
\text { Positivos }\end{array}$} & 1 & 4,77 & 0,53 & $11,07 \%$ & \multirow{9}{*}{4,63} & \multirow{9}{*}{0,73} & \multirow{9}{*}{$15,69 \%$} \\
\hline & 2 & 4,50 & 0,60 & $13,28 \%$ & & & \\
\hline & 3 & 4,77 & 0,53 & $11,07 \%$ & & & \\
\hline & 4 & 4,64 & 0,95 & $20,56 \%$ & & & \\
\hline & 5 & 4,68 & 0,57 & $12,13 \%$ & & & \\
\hline & 6 & 4,68 & 0,89 & $19,09 \%$ & & & \\
\hline & 7 & 4,59 & 0,67 & $14,51 \%$ & & & \\
\hline & 8 & 4,59 & 1,01 & $21,95 \%$ & & & \\
\hline & 9 & 4,45 & 0,67 & $15,06 \%$ & & & \\
\hline \multirow{12}{*}{$\begin{array}{c}\text { Afetos } \\
\text { Negativos }\end{array}$} & 1 & 1,36 & 0,73 & $53,29 \%$ & \multirow{12}{*}{1,24} & \multirow{12}{*}{0,74} & \multirow{12}{*}{$59,24 \%$} \\
\hline & 2 & 1,05 & 0,21 & $20,39 \%$ & & & \\
\hline & 3 & 1,00 & 0,00 & $0,00 \%$ & & & \\
\hline & 4 & 1,00 & 0,00 & $0,00 \%$ & & & \\
\hline & 5 & 1,14 & 0,64 & $56,28 \%$ & & & \\
\hline & 6 & 1,18 & 0,66 & $56,23 \%$ & & & \\
\hline & 7 & 2,50 & 1,50 & $60,16 \%$ & & & \\
\hline & 8 & 1,05 & 0,21 & $20,39 \%$ & & & \\
\hline & 9 & 1,14 & 0,47 & $41,15 \%$ & & & \\
\hline & 10 & 1,23 & 0,61 & $49,86 \%$ & & & \\
\hline & 11 & 1,23 & 0,69 & $55,84 \%$ & & & \\
\hline & 12 & 1,05 & 0,21 & $20,39 \%$ & & & \\
\hline \multirow{5}{*}{$\begin{array}{c}\text { Realizaçã } \\
\text { o }\end{array}$} & 1 & 4,50 & 0,67 & $14,95 \%$ & \multirow{5}{*}{4,49} & \multirow{5}{*}{0,82} & \multirow{5}{*}{$18,18 \%$} \\
\hline & 2 & 4,77 & 0,43 & $8,99 \%$ & & & \\
\hline & 3 & 4,36 & 0,79 & $18,09 \%$ & & & \\
\hline & 4 & 4,05 & 1,36 & $33,67 \%$ & & & \\
\hline & 5 & 4,45 & 0,86 & $19,26 \%$ & & & \\
\hline
\end{tabular}




\begin{tabular}{|c|c|c|c|}
6 & 4,64 & 0,58 & $12,53 \%$ \\
\hline 7 & 4,14 & 0,99 & $23,94 \%$ \\
\hline 8 & 4,77 & 0,43 & $8,99 \%$ \\
\hline 9 & 4,77 & 0,53 & $11,07 \%$ \\
\hline
\end{tabular}

Quadro 2. Construtos relacionados a aspectos de Felicidade no Trabalho Fonte: Dados da pesquisa (2014)

Em relação ao primeiro constructo, “Afetos Positivos”, se buscou saber o quão elevado é o bem-estar dos voluntários, pois este aumenta à medida que crescem os aspectos considerados positivos no trabalho, a exemplo da disposição, do entusiasmo, etc., elementos estes que compõem a escala utilizada (Paschoal et al., 2010).

A média encontrada no primeiro constructo corresponde a 4,63, a qual, diante da variação da escala ( 1 a 5), pode ser considerada alta, sugerindo que os itens relacionados a emoções positivas aparecem em maior constância entre os voluntários do Acesso Cidadão. Esse dado pode ser reafirmado a partir da análise do desvio padrão do quesito, que corresponde a 0,73, valor relativamente baixo, e a 15,69\% do coeficiente de variância, que indica certa homogeneidade entre as respostas. Desse modo, é possível perceber que os afetos positivos são superiores aos negativos e estão quase no mesmo nível dos elementos de Realização, levando ao entendimento de que existem traços de bem-estar no trabalho (Paschoal, 2008).

Ao serem indagados sobre as sensações referentes ao trabalho que realizaram nas últimas semanas no Acesso Cidadão, os voluntários evidenciaram aspectos de "Alegria” e “Contentamento” em suas respostas. As médias para essas questões foram as mais altas do quesito, ambas no valor de 4,77, número próximo a média geral do construto, o que implica a prevalência de emoções positivas no trabalho, caracterizando aspectos de bem-estar (Paschoal \& Tamayo, 2008).

Em relação aos Afetos Negativos, segundo constructo analisado, obteve-se uma média de 1,24, a qual pode ser considerada baixa. Essa ideia reforça-se a partir da análise do coeficiente de variância e do desvio-padrão da variável, sendo de 59,24\% e 0,74, respectivamente, o que representa um quadro de respostas discrepantes. O quesito “Ansioso", por sua vez, apresentou a maior média do grupo (2,50), com variância de 60,16\% e desvio de 1.50. Essa questão aponta uma possível reação dos voluntários ao trabalho realizado.

Entende-se que, para alguns, a ansiedade em relação ao Projeto Acesso Cidadão referese a algo positivo, como uma sensação agradável de espera pelo sábado, dia em que é 
realizado o projeto, por isso a existência de algumas respostas variando para a ponta direita da escala, que expressa concordâncias extremas. Por outro lado, os respondentes que associaram "Ansiedade” a um contexto negativo, possivelmente acreditam que tal elemento não condiz com as sensações por eles obtidas no trabalho voluntário, atribuindo as respostas, discordâncias.

Dois elementos que merecem destaque no tocante aos Afetos Negativos, dizem respeito às respostas 3 e 4 ("Deprimido" e "Entediado"), ambas obtendo médias no valor 1,00, com desvio-padrão de 0,00 e variância de $0,00 \%$. Isso indica que todos os respondentes assinalaram a mesma resposta no questionário. Esse fato, pode ter incidido em decorrência a dinâmica do projeto, que prevê constante interação entre os voluntários e os beneficiados através das atividades realizadas.

O terceiro constructo analisado, Realização, diz respeito a percepção do voluntário sobre o desenvolvimento de suas habilidades no trabalho para o alcance de suas metas de vida (Paschoal \& Tamayo, 2008). Combinado com os Afetos Positivos, esses constructos sugerem elevados níveis de bem-estar entre os trabalhadores. Tal construto obteve média de 4,49, sugerindo que a realização pessoal dos voluntários com o trabalho desempenhado no Projeto Acesso Cidadão, é alta. Essa afirmativa é reforçada pelas medidas do desvio-padrão de 0,82 e coeficiente de variância no valor de 18,18\%, como foi apresentado no Quadro 2, o que significa que há regularidade nas respostas.

Nesta variável se destaca a questão 4 “Consigo recompensas para mim”, que obteve a menor média do grupo $(4,05)$ e o maior coeficiente de variância $(33,67 \%)$, mostrando dissonância entre as respostas obtidas. No entanto, pode-se observar que, ainda assim, o valor da média é alta. Possivelmente, os respondentes entendem recompensa não apenas no sentido monetário, pois o trabalho é voluntário, mas, sim, em termos afetivos, emocionais, etc. agregando a pergunta, uma conotação positiva.

Desse modo, pressupõe-se que os Afetos Positivos, assim como as Realizações, prevalecem sobre os Afetos Negativos, sinalizando aspectos de bem-estar, no sentido trabalhado nesta pesquisa (sinônimo de felicidade), no trabalho desenvolvido pelos voluntários do Acesso Cidadão (Paschoal et al., 2010). Contudo, faz-se necessário relacionar os elementos trabalhados até o momento, felicidade e motivação, a fim de que se possa atingir o objetivo da presente pesquisa.

Assim, buscando-se relacionar esses dois elementos, foi realizada uma correlação estatística, através do programa SPSS, entre os dados de Felicidade e Motivação. Decidiu-se 
por analisar apenas as correlações significativas, aquelas que possuem nível de significância abaixo de ,o05. Foram constatadas 10 correlações significativas, as quais estão expostas no Quadro 3.

\begin{tabular}{|c|c|c|c|c|c|}
\hline \multirow{2}{*}{$\begin{array}{c}\text { Fatores } \\
\text { Motivacion } \\
\text { ais }\end{array}$} & \multirow{2}{*}{$\begin{array}{c}\text { Análise } \\
\text { Estatística }\end{array}$} & \multicolumn{4}{|c|}{ Fatores de Felicidade } \\
\hline & & Alegre & $\begin{array}{l}\text { Dispos } \\
\text { to }\end{array}$ & $\begin{array}{c}\text { Empolga } \\
\text { do }\end{array}$ & $\begin{array}{l}\text { Orgulho } \\
\text { so }\end{array}$ \\
\hline \multirow{2}{*}{$\begin{array}{l}\text { Ajudar os } \\
\text { Outros }\end{array}$} & $\begin{array}{l}\text { Pearson } \\
\text { Correlation }\end{array}$ & $.588^{* *}$ &, $816^{* *}$ &, $538^{* *}$ & $635^{* * *}$ \\
\hline & Sig. (2-tailed) & ,004 & ,000 & ,010 & ,002 \\
\hline \multirow{3}{*}{$\begin{array}{l}\text { Mudar a } \\
\text { Vida das } \\
\text { Pessoas }\end{array}$} & & \multicolumn{4}{|c|}{ Entusiasmado } \\
\hline & $\begin{array}{l}\text { Pearson } \\
\text { Correlation }\end{array}$ & \multicolumn{4}{|c|}{, $563^{* *}$} \\
\hline & Sig. (2-tailed) & \multicolumn{4}{|c|}{,006 } \\
\hline \multirow{3}{*}{$\begin{array}{c}\text { Permitir } \\
\text { que as } \\
\text { pessoas } \\
\text { tenham } \\
\text { oportunida } \\
\text { de de viver }\end{array}$} & & $\begin{array}{c}\text { Entusiasma } \\
\text { do }\end{array}$ & \multicolumn{3}{|c|}{ Atinjo resultados que valorizo } \\
\hline & $\begin{array}{l}\text { Pearson } \\
\text { Correlation }\end{array}$ & $.548^{* *}$ & \multicolumn{3}{|c|}{$.572^{* * *}$} \\
\hline & Sig. (2-tailed) & ,008 & \multicolumn{3}{|c|}{,005 } \\
\hline \multirow{3}{*}{$\begin{array}{c}\text { Ser } \\
\text { membro } \\
\text { útil na } \\
\text { comunidad } \\
\text { e em que } \\
\text { vivo }\end{array}$} & & \multicolumn{4}{|c|}{ Com raiva } \\
\hline & $\begin{array}{l}\text { Pearson } \\
\text { Correlation }\end{array}$ & \multicolumn{4}{|c|}{$-.567^{* *}$} \\
\hline & Sig. (2-tailed) & \multicolumn{4}{|c|}{,006 } \\
\hline \multirow{3}{*}{$\begin{array}{c}\text { Fazer parte } \\
\text { de um } \\
\text { grupo }\end{array}$} & & \multicolumn{4}{|c|}{ Realizo meu potencial } \\
\hline & $\begin{array}{l}\text { Pearson } \\
\text { Correlation }\end{array}$ & \multicolumn{4}{|c|}{$-.708^{* * *}$} \\
\hline & Sig. (2-tailed) & \multicolumn{4}{|c|}{,000 } \\
\hline \multirow{3}{*}{$\begin{array}{c}\text { Aprender a } \\
\text { lidar com } \\
\text { pessoas }\end{array}$} & & \multicolumn{4}{|c|}{ Realizo meu potencial } \\
\hline & $\begin{array}{l}\text { Pearson } \\
\text { Correlation }\end{array}$ & \multicolumn{4}{|c|}{$-.605^{* *}$} \\
\hline & Sig. (2-tailed) & \multicolumn{4}{|c|}{,003 } \\
\hline
\end{tabular}

Quadro 3. Correlação entre fatores de motivação e felicidade no trabalho voluntário Fonte: Dados da Pesquisa (2014)

Dentre os fatores motivacionais quatro apresentaram fortes correlações entre os elementos de felicidade, sendo eles os elementos que compõem os níveis Altruísta, Afetivo, Amigável e Ajustado. Quanto aos aspectos de felicidade, destacaram-se seis Afetos Positivos, um Afeto Negativo e três componentes do quesito Realização, sendo válido destacar que estas últimas correlações foram negativas. 
As primeiras correlações analisadas, englobam elementos Altruístas e Afetos Positivos. A questão "Ajudar os outros" foi correlacionada a quatro fatores positivos de bem-estar, sejam eles: “Alegre”, "Disposto", “Empolgado” e "Orgulhoso”. Analisando a primeira correlação, percebe-se que a medida que se aumenta a possibilidade de ajudar os outros, aumenta-se a probabilidade de sentir-se alegre naquilo que se está realizando. Também foi possível perceber que ao passo que aumenta a motivação em ajudar os outros, também se eleva a disposição, empolgação e o orgulho no trabalho executado.

Esses resultados reforçam a ideia de que o voluntariado é desempenhado a partir dos valores que os indivíduos possuem (Cavalcante, 2012). Neste caso, pode-se induzir a ideia de que os voluntários são motivados através de valores positivos, de caridade, que se desdobram, ficam transparentes através das emoções, afetos, também positivos, como a alegria e a disposição em auxiliar os outros.

Continuando a análise dos elementos motivacionais altruístas, têm-se que a questão "Mudar a vida das pessoas" está positivamente correlacionada ao elemento "Entusiasmo", o que indica que, estatisticamente, quanto mais o voluntário se motiva a mudar a vida das pessoas através de seu trabalho, mais entusiasmado ele fica com o mesmo. Esse entusiasmo também é refletido através do aumento do elemento "Permitir que as pessoas tenham oportunidade de viver”. Como o Acesso Cidadão se trata de um projeto que busca levar a promoção de lazer (entendido dentro de um contexto de 'oportunidade de viver", dado a condição dos beneficiados), os elementos em questão, entusiasmam os voluntários, os quais, à medida que conseguem proporcionar tais fatos, mais motivados e felizes ficam.

A última correlação positiva diz respeito ao fator Altruísta "Permitir que as pessoas tenham oportunidade de viver" com os aspectos de Realização "Atinjo resultados que valorizo". A partir desta podemos inferir que à medida que o voluntário atinge resultados que valoriza, mais motivado ele fica a permitir que as pessoas tenham oportunidade de viver, pois acredita no trabalho que está executando. Desdobrando os números, pode-se entender que no momento em que os voluntários vêem seu trabalho tendo efeito, à medida que eles proporcionam aos deficientes e demais beneficiários, possibilidades antes quase nulas, eles enxergam seu trabalho como algo valioso, algo que acreditam ser positivo para a sociedade.

Passando para as correlações negativas, têm-se fatores Afetivos, Amigáveis e Ajustados, fazendo conexão com Afetos Negativos e aspectos de Realização. A primeira dessas correlações ("Ser membro útil na comunidade em que vivo" e "Com raiva”, correspondentes ao Nível Afetivo da Motivação e Afeto Negativo de Felicidade, 
respectivamente) demonstra que quanto mais o voluntário se sente membro útil na comunidade em que vive, menos raiva ele sente do trabalho realizado na mesma.

A segunda relação negativa diz respeito a realização do potencial dos voluntários e da participação em um grupo. Através dela, percebe-se que os voluntários não necessitam fazer parte de um grupo para realizarem seu potencial. O fator "fazer parte de um grupo" foi a que obteve média mais baixa dentro de sua categoria. Desse modo, não pode ser classificado como motivação dos voluntários do Acesso Cidadão. Assim, podemos entender que o potencial dos voluntários não é afetado pela necessidade de pertença a um grupo.

Por fim, a última correlação (“Aprender a lidar com pessoas” e "Realizo meu potencial” correspondentes ao nível motivacional Ajustado e aos aspectos de Realização) evidencia que quanto mais o voluntário aprende a lidar com pessoas, desenvolvendo habilidade de autoconhecimento, menos o voluntário acredita está realizando todo o seu potencial. Supõese que os voluntários do Acesso Cidadão acreditam que seu potencial possa ir além, pois não o adentram com esse fim, contudo, essa é uma consequência do trabalho que realizam no projeto.

\section{Implicações Para a Teoria}

A partir de estudos realizados, a exemplo de Souza et al. (2010) e Parizotto e Freitas (2015), a prática do trabalho voluntário impacta positivamente na qualidade de vida, no domínio psicológico e na avaliação global dos indivíduos que o praticam, produzindo assim uma efetiva felicidade nos mesmos, uma vez que estes encontraram a capacidade de fazer algo por outra pessoa, sem buscar dinheiro em troca. No entanto, diante desta constatação se faz relevante destacar que os motivos que levam um indivíduo a engajar-se no voluntariado variam entre as pessoas a depender das individualidades de cada um, das diferentes situações e do contexto.

Neste sentido, conforme demonstra Cavalcante (2012), às atitudes substantivas de ajuda voluntária ao próximo podem ser impulsionadas por motivações que variam desde as altruístas à egoístas, e, portanto, a lacuna teórica deste estudo está em analisar a relação existente entre diferentes motivações e felicidade no trabalho dos voluntários. Assim, a partir da obtenção e análise dos dados, confirmou-se a expectativa de que o trabalho voluntário pode influenciar na motivação dos voluntários, assim como na felicidade dos mesmos. 


\section{Implicações Para a Prática}

Conforme a apresentação da análise dos resultados, identificou-se que os fatores nos quais se destacaram foram: o altruísta, especificamente o "ajudar" aos outros e "mudar a vida das pessoas", bem como o fator afetivo, a exemplo de "ser útil na comunidade". Nesse sentido, acredita-se que a ONG poderá aprimorar sua gestão em cima destas informações, podendo assim desenvolver ações nos sistemas de "recompensas intrínsecas", tais como: Permitir maior participação dos voluntários, seja com sugestões ou atitudes práticas, para elaboração de novas atividades da ONG, de modo que estes sintam-se cada vez mais úteis na promoção da melhoria de vida daqueles que a entidade assiste. Uma outra sugestão seria a prática de feedbacks regulares demonstrando os efeitos que as atividades promovidas têm causado na vida das pessoas, pois assim, os voluntários terão uma maior dimensão do impacto das suas ações no processo de ajudar e mudar a vida do outro.

Diante dos exemplos apresentados quanto às possíveis tomadas de decisões com base nos resultados desta pesquisa, acredita-se ser possível influenciar positivamente a satisfação dos voluntários atuantes, podendo gerar uma diminuição no índice de rotatividade dos indivíduos, além de atrair novos colaboradores voluntários para o desenvolvimento das atividades.

\section{Conclusões}

O trabalho voluntário foi caracterizado no decorrer desta pesquisa como uma atividade realizada de forma espontânea, não remunerada e composta por elementos motivacionais diferentes daqueles associados a um trabalho assalariado. Foi diante desta constatação que se buscou descobrir quais as motivações dos que realizam este tipo de atividade. Junto a tal questionamento, também se buscou saber a relação destes elementos com felicidade.

Diante do exposto no referencial teórico, se pôde perceber que as pessoas felizes também experimentam afetos negativos, ou seja, esses não significam, necessariamente, que não exista felicidade no trabalho. Esse tipo de afeto pode aparecer nas respostas, mas ainda assim, a felicidade, o bem-estar, podem estar imbricados com o trabalho.

Quando analisados os fatores relacionados ao bem-estar, os afetos negativos praticamente não apareceram nos resultados. Em especial, destacam-se as respostas 
“deprimido" e "entediado", que obtiveram médias no valor 1,oo, dentro de uma escala de 1 à 5. As médias baixas de todo constructo "Afetos Negativos" podem ser justificadas pelas características da instituição em que atuam, o Acesso Cidadão. Desse modo, podemos entender que o tipo de instituição (auxílio de deficientes, crianças carentes, presidiários, etc.) que promove o trabalho voluntário pode influenciar na motivação dos voluntários, assim como na felicidade. Como a instituição em questão promove dentre outras coisas, o lazer às pessoas com deficiência, através, de banhos de mar, por exemplo, possibilitando a indivíduos que, em muitos casos, nunca haviam tido esta experiência, os voluntários ao responderem a pesquisa, transparecem sentimentos positivos em relação ao seu trabalho, mostrando-se, em sua maioria realizados, felizes.

Foi possível identificar, através das análises dos dados, que fatores altruístas como "ajudar" os outros, "mudar a vida das pessoas", fatores afetivos, a exemplo de "ser útil na comunidade", etc. motivam os voluntários do Acesso Cidadão. Também foi observado que o Fator Ajuizado não apareceu nas correlações. Uma possível resposta seria a de que este fator foi o mais baixo na hierarquia das motivações. Por outro lado, foi possível perceber que fatores considerados egoístas, como "sentir-se importante", ou até mesmo "ser reconhecido", não motivam os entrevistados. Isso ressalta a ideia de que o trabalho voluntário é uma atividade realizada com doação, olhando para o próximo.

Por fim, retorna-se ao início deste estudo, onde se indaga a possibilidade da felicidade estar relacionada à motivação do trabalho voluntário. Através da análise das correlações foi possível perceber que sim. As correlações dos elementos altruístas mostraram que aspectos representativos da felicidade, como alegria, disposição, empolgação, etc. aparecem quando o voluntário ajuda os outros, quando consegue mudar a vida das pessoas, como foi comentado. O "Mudar a vida das pessoas", "Ajudar os outros", no âmbito do projeto, se refere especificamente a levar alegria, felicidade aos beneficiados, como dito, através de um banho de mar ou mesmo de uma partida de vôlei na areia. Desse modo, concluímos afirmando que a felicidade tanto é elemento motivador dos voluntários como também é elemento repassado aos beneficiados.

\section{Limitações da Pesquisa}


Apesar de resultados encorajadores, que podem conduzir a outros estudos, a exemplo de estudos qualitativos, deve ser reconhecido que a limitação da amostra impede uma maior generalização dos resultados.

\section{Sugestões Para Pesquisas Futuras}

Diante do exposto em toda a pesquisa verificou-se que o que naturalmente pode ser um fator motivador para o envolvimento no trabalho voluntário, como o pertencimento a um grupo específico, não se demonstrou uma realidade na ONG em análise. O fator "fazer parte de um grupo", apresentou a menor média dentre a análise, levando-nos a concluir que pertencer a ONG Acesso Cidadão configura-se como consequência do trabalho voluntário, mas não pode ser considerada um aspecto motivador para os indivíduos respondentes.

Nesta perspectiva, nos testes de correlações, o fator "fazer parte de um grupo" também foi a que obteve a média mais baixa quando correlacionada a felicidade, indicando que o potencial dos voluntários não é afetado pela necessidade de pertencimento a um grupo e, por isso este fator não é responsável por deixá-los mais felizes.

A partir destes dados, sugere-se como pesquisa futura um estudo qualitativo na ONG Acesso Cidadão para uma melhor compreensão das causas pelas quais o grupo que compõe a mesma não está deixando os voluntários felizes, nem tão pouco influenciando nas suas motivações. 


\section{Referências}

Ageu, J. D. (2015). Motivações de permanência no trabalho voluntário: um estudo na Fundação Cidade Viva. (Dissertação de Mestrado). Universidade Federal da Paraíba, João Pessoa.

http://tede.biblioteca.ufpb.br/bitstream/tede/7951/2/arquivototal.pdf

Albuquerque, A. S., \& Tróccoli, B. T. (2004). Desenvolvimento de uma escala de bem-estar subjetivo. Psicologia: teoria e pesquisa, 2O(2), 153-164.

Aquino, M. A. G. D. (2015). Expectativas, adesão e desligamento no trabalho voluntário: estudos de motivos do voluntariado da Fundação Cidade Viva. (Dissertação de Mestrado). Universidade Federal da Paraíba, João Pessoa. Recuperado de http://tede.biblioteca.ufpb.br/bitstream/tede/7954/2/arquivototal.pdf

Bussell, H., \& Forbes, D. (2002). Understanding the volunteer market: The what, where, who and why of volunteering. International Journal of Nonprofit and Voluntary Sector Marketing, $7(3)$, 244-257.

Caissie, L. T., \& Halpenny, E. A. (2003). Volunteering for nature: Motivations for participating in a biodiversity conservation volunteer program. World Leisure Journal, $45(2), 38-50$.

Cavalcante, C. E. (2012). Motivação no trabalho voluntário: expectativas e motivos na Pastoral da Criança.

Cavalcante, C. E. (2016) Motivação de Voluntários: teoria e prática. Curitiba: Appris Editora.

Cavalcante, C. E., Souza, W. J., Cunha, A. S. R., \& Nascimento, M. A. A. (2010). Comportamento organizacional no trabalho voluntário: motivos, perfis e correlações na Pastoral da Criança. Estudos do CEPE, 97-132.

Cavalcante, C. E., Souza, W. J., da Cunha, A. S. R., Nascimento, M. A. A., \& Fernandes, L. T. (2012). " Por que sou voluntário?": etapa de construção de Escala. Revista Pretexto, 13(2), 76-90. 
Clary, E. G., Snyder, M., \& Ridge, R. (1992). Volunteers' motivations: A functional strategy for the recruitment, placement, and retention of volunteers. Nonprofit Management and Leadership, 2(4), 333-350.

Cnaan, R. A., Handy, F., \& Wadsworth, M. (1996). Defining who is a volunteer: Conceptual and empirical considerations. Nonprofit and voluntary sector quarterly, 25(3), 364-383.

Cravens, J. (2014). Internet-mediated Volunteering in the EU: Its history, prevalence, and approaches and how it relates to employability and social inclusion (No. JRC85755). Joint Research Centre (Seville site).

Daniels, K. (2000). Measures of five aspects of affective well-being at work. Human Relations, 53(2), 275-294.

Diener, E., Scollon, C. N., \& Lucas, R. E. (2003). The evolving concept of subjective wellbeing: The multifaceted nature of happiness. Advances in cell aging and gerontology, 15(2), 187-219. doi: 10.1016/S1566-3124(03)15007-9

Ferreira, M. R., Proença, T., \& Proença, J. F. (2008). As motivações no trabalho voluntário. Revista Portuguesa e Brasileira de Gestão, 7(3), 43-53.

Figueiredo, N. C. M. (2005). Interfaces do trabalho voluntário na aposentadoria. (Dissertação de Mestrado). Universidade Federal do Rio Grande do Sul, Porto Alegre.

Fischer, L. R., \& Schaffer, K. B. (1993). Older volunteers: A guide to research and practice. Sage Publications, Inc.

Gomide Júnior, S., Silvestrin, L. H. B., \& Oliveira, Á. D. F. (2015). Bem-estar no trabalho: o impacto das satisfações com os suportes organizacionais e o papel mediador da resiliência no trabalho. Revista Psicologia Organizações e Trabalho, 15(1), 19-29.

Lemos, S. L. L. (2016). Motivação para expectativa, entrada, permanência e saída: um estudo longitudinal no voluntariado da Fundação Cidade Viva. (Dissertação de Mestrado). Universidade Federal da Paraíba, João Pessoa. Recuperado de http://tede.biblioteca.ufpb.br:808o/handle/tede/8609

Lum, T. Y., \& Lightfoot, E. (2005). The effects of volunteering on the physical and mental health of older people. Research on aging, 27(1), 31-55. 
Mostyn, B. (1983). The meaning of voluntary work: a qualitative investigation. Volunteers: Patterns, meanings and motives, 24-50.

Musick, M. A., \& Wilson, J. (2008). Volunteers: A social profile. Indiana University Press.

Parizotto, A. P. V., \& Freitas, A. P. (2015). Percepções de voluntários em um hospital universitário sobre o desenvolvimento de atividades lúdicas: a arte de se doar ao outro. Pesquisa em Psicologia-anais eletrônicos.

Paschoal, T. (2008). Bem-estar no trabalho: Relações com suporte organizacional, prioridades axiológicas e oportunidades de alcance de valores pessoais no trabalho. (Tese de Doutorado). Universidade de Brasília, Brasília.

Paschoal, T., \& Tamayo, A. (2008). Construção e validação da escala de bem-estar no trabalho. Avaliação psicológica, 7(1), 11-22.

Paschoal, T., Torres, C. V., \& Porto, J. B. (2010). Felicidade no trabalho: Relações com suporte organizacional e suporte social. Revista de Administração Contemporânea, 14(6), 1054

Paz, M. D. G. T., \& Tamayo, A. (2004). Poder e saúde organizacional. Cultura e saúde nas organizações, 127-154.

Pearce, J. L. (1983). Comparing volunteers and employees in a test of Etzioni's compliance typology. Journal of Voluntary Action Research, 12(2), 22-30.

Penner, L. A. (2002). Dispositional and organizational influences on sustained volunteerism: An interactionist perspective. Journal of Social Issues, 58(3), 447-467.

Piccoli, P., \& Godoi, C. K. (2009, novembro). Motivação para o trabalho voluntário contínuo: um estudo etnográfico no Núcleo Espírita Nosso Lar. In Encontro de Gestão de Pessoas e Relações de Trabalho, Curitiba, 2.

Prouteau, L., \& Wolff, F. C. (2008). On the relational motive for volunteer work. Journal of Economic Psychology, 29(3), 314-335. 
Rocha Sobrinho, F., \& Porto, J. B. (2012). Bem-estar no trabalho: um estudo sobre suas relações com clima social, coping e variáveis demográficas. RAC-Revista de Administração Contemporânea, 16(2).

Rose-Ackerman, S. (1996). Altruism, nonprofits, and economic theory. Journal of economic literature, 34(2), 701-728.

Ryan, R. M., \& Deci, E. L. (2001). On happiness and human potentials: A review of research on hedonic and eudaimonic well-being. Annual review of psychology, 52(1), 141-166.

Silva, J. O. (2004). Voluntário: quem é, por que é e por que deixa de ser. In J.O. Silva. (Org.). Novo voluntariado social: teoria e ação (pp. 113-135). Porto Alegre: Dacasa.

Silva, N., \& Tolfo, S. D. R. (2012). Trabalho significativo e felicidade humana: explorando aproximações. Revista Psicologia Organizações e Trabalho, 12(3), 341-354.

Siqueira, M. M. M., \& Padovam, V. A. R. (2008). Bases teóricas de bem-estar subjetivo, bemestar psicológico e bem-estar no trabalho. Psicologia: teoria e pesquisa, 24(2), 201-209.

Souza, L. M., Lautert, L., \& Hilleshein, E. F. (2010). Trabalho voluntário, características demográficas, socioeconômicas e autopercepção da saúde de idosos de Porto Alegre. Revista da Escola de Enfermagem da USP, 44(3).

Souza, W. D., Medeiros, J. D., \& Fernandes, C. L. (2006, dezembro). Trabalho voluntário: elementos para uma tipologia. Colóquio Internacional sobre Poder Local, Salvador, 10, p. 1-16.

Souza, W. J., \& Medeiros, J. P. (2012). Trabalho voluntário: Motivos para sua realização. Revista de Ciências da Administração, 14(33), 93.

Tang, F., Morrow-Howell, N., \& Hong, S. (2009). Institutional facilitation in sustained volunteering among older adult volunteers. Social Work Research, 33(3), 172-182.

Teodósio, A. D. S. (2002). Voluntariado: Entre a utopia e a realidade da mudança social. Anais do Encontro Anual da Associação Nacional de Pós-Graduação em Administração. Recife, 26. 
DOI: http://dx doi.org/10 $21714 / 2238-104 \mathrm{X}_{2017}$

Trogdon, S. E. II. (2005). A study of parks and recreation citizen board members in North Carolina and their motivations for participation. (Dissertação de Mestrado). Faculty of North Carolina State University, Raleigh.

Unger, L. S. (1991). Altruism as a motivation to volunteer. Journal of Economic Psychology, 12(1), 71-100.

Yeung, A. B. (2004). The octagon model of volunteer motivation: Results of a phenomenological analysis. Voluntas: International Journal of Voluntary and Nonprofit Organizations, 15(1), 21-46. 